Original Research Paper

\title{
Thermal Hydraulic Analysis of Double Ended Hot Leg Pipeline Break Accident in AP1000 Reactor
}

\author{
${ }_{1,2 *}$ M.M. Sadeghiazad and ${ }^{2}$ F. Choobdar Rahim \\ ${ }^{I}$ Department of Mechanical Engineering, Azarbaijan Shahid Madani University, Tabriz, Iran \\ ${ }^{2}$ Department of Mechanical Engineering, Urmia University of Technology, Urmia, Iran
}

\begin{abstract}
Article history
Received: $13-03-2020$

Revised: 02-05-2020

Accepted: 13-05-2020

Corresponding author:

M.M. Sadeghiazad

Department of Mechanical

Engineering, Azarbaijan Shahid

Madani University, Tabriz, Iran and

Department of Mechanical Engineering, Urmia University of Technology, Urmia, Iran. Email:m.sadeghiazad@azaruniv.ac.ir m.sadeghiazad@uut.ac.ir
\end{abstract}

\begin{abstract}
In the present research, the Loss of Coolant Accident (LOCA), as a postulated accident in nuclear reactors, in its worst condition called large LOCA has been modeled. A specific type of large LOCA in which a totally guillotine break occurs in the hot leg pipe is the Double Ended Hot Leg (DEHL). Once the 'LOCA' occurs, the pipe is break and the coolant is lost and as a result, the danger of core melting is expected. In this paper, the single volume method was used to perform the numerical modeling on AP1000 reactor, a pressurized water reactor, which is among the most complex safe reactors that have been made so far. A wide range of safety margins are provided by its safety systems. The passivity is one of the most important safety features of AP1000 by which several simplifications can be made so that safety, reliability, construction, operation, maintenance, investment, protection and plant costs can be enhanced. Analyzing the most dangerous accident in one of the most secure reactors can be considered a valuable and logical work. The MATLAB software was used to perform the numerical analysis. Finally, the results obtained from the analysis were compared with the reports on the safety, security and environmental of AP1000 reactor.
\end{abstract}

Keywords: AP1000 Reactor, Hot Leg, DEHL, Containment, Single Volume, Heat Transfer

\section{Introduction}

The AP1000 is a GEN III+ nuclear reactor designed by Westinghouse Electric Company. It is an improved Pressurized Water Reactor (PWR) design with the feature of passive cooling. The AP1000 has two Reactor Coolant System (RCS) loops with a typical thermal power of 3400 MWt. The AP1000 containment is also improved from the traditional large dry containment. If a Loss-Of-Coolant Accident (LOCA) occurs, the containment can still maintain its structural integrity after accommodating the blow-down fluid (Hung et al., 2015). During a severe accident, a large amount of radioactive fission products can be generated and the aim of the containment system is to avoid or limit the release of these fission products to the external environment (Oriolo and Paci, 2000; Choobdar Rahim et al., 2012). This aim will be achieved by restriction of accidents or when an accident occurred, containment safety systems limit the dangerous effects of event. Therefore containment plays basic roles in safety. AP1000 is a two loop 1000 MWe Pressurized Water Reactor (PWR) with passive safety features and extensive plant simplifications that enhance the construction, operation, maintenance and safety (Rahim and Yousefi, 2012). Major advances of AP1000 design over conventional plant designs include the following: AP1000 safety features rely on natural driving forces, such as pressurized gas, gravity flow, natural circulation flow and convection. These features do not use active components, such as pumps, fans, chillers, or diesel generators. These features are designed to function without active safety support systems, such as AC power, component cooling water, service water and Heating Ventilation and Air Conditioning (HVAC) (Saiu and Frogheri, 2005). AP1000 is a PWR power reactor which its safety features establish and maintain core cooling and containment integrity indefinitely, with no operator action or $\mathrm{AC}$ power following design basis faults. These systems contain significantly fewer components, reducing required tests, inspections and maintenance, their readiness is easily monitored (UK Compliance document for AP1000 design, 1000). The AP1000 safety-related systems include the following (Fig. 1) (Rahim and Yousefi, 2012):

1. Passive core cooling System (PXS)

2. Passive Containment cooling System (PCS) 
3. Main control room emergency habitability system (VES)

\section{Containment isolation}

AP1000 safety features establish and maintain core cooling and containment integrity indefinitely, with no operator action or AC power following design basis faults. These systems contain significantly fewer components, reducing required tests, inspections and maintenance, also their readiness is easily monitored (U.S.NRC, 2004).

The loss of coolant is most likely in the water cooled reactors where the stored energy content of the high pressure, high temperature coolant may be released to the containment by rupture of an exposed pipe. Design basis analysis of LWR systems calls for the following scenario:

1) A double ended "guillotine" pipe break in a primary coolant line to allow free coolant flow from both ends

2) Coolant flashes to steam under the influence of the stored energy and is discharged rapidly into the containment building

3) Although the coolant loss shuts down the system neutronically, reactor trip is initiated by an underpressure reading to the protective system to assure continued sub criticality

4) The emergency core cooling systems (ECCS) operate to cool the core and prevent excessive decay heat driven damage

5) Radioactivity in the coolant is retained by the containment structure with natural deposition processes and active removal systems eventually reducing overall levels of radioactivity

6) Heat removal systems maintain ECCS effectiveness and reduce containment pressure. As in the LOCA, design features are expected to mitigate the consequences of the accident to minimize the amount of fuel failure and subsequent release of radioactivity for each of the reactor design. Figure 2 and 3 show reactor and containment and the constitutive components of AP1000 containment cooling systems

The most dangerous accidents in reactor containments known as Loss of Coolant Accident (LOCA) in its worst condition called large LOCA has been modeled (Choobdar Rahim et al., 2012), A previous works was presented the simulation of the AP1000 reactor containment pressurized during loss of coolant (Rahim and Yousefi, 2012), Simulation of AP1000's passive containment cooling with the German Containment Code System COCOSYS (Broxtermann and Allelein, 2013), Analysis of AP1000 containment passive cooling system during a loss-of-coolant accident (Hung et al., 2015), Numerical simulation of AP1000 LBLOCA with SCDAP/RELAP 4.0 code (Xie, 2017), Simulation and Analysis of Small Break LOCA for AP1000 Using RELAP5-MV and Its Comparison with NOTRUMP Code (Yousif et al., 2017), Thermal-hydraulic and stress analysis of AP1000 reactor containment during LOCA in dry cooling mode (Sheykhi et al., 2017), Simulation and analysis on 10-in. cold leg small break LOCA for AP1000 (Yang et al., 2012), Analysis of reactor coolant system leak for AP1000 nuclear power plant (Zheng Limin, 2016) and Simulation Of Containment Pressurization In A Large Break-Loss Of Coolant Accident Using SingleCell and Multi-cell Models and CONTAIN Code (Noori-Kalkhoran et al., 2016).

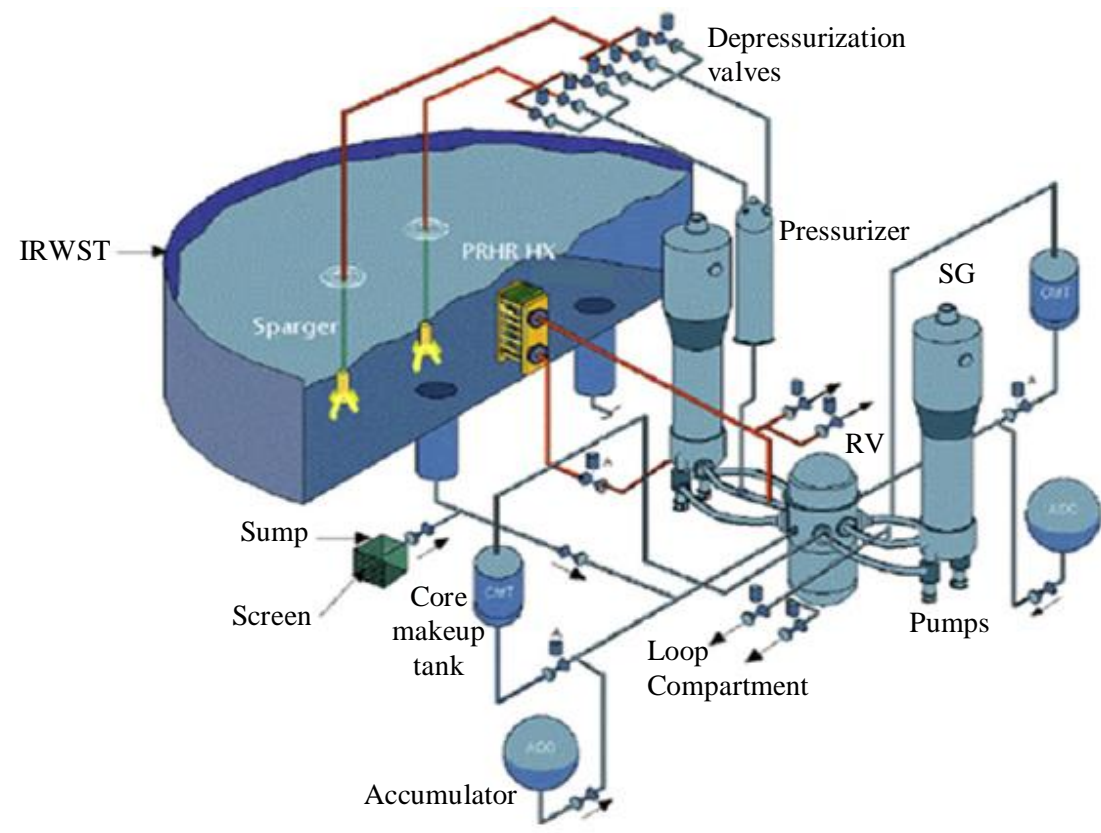

Fig. 1: AP1000 RCS and Passive Core Cooling System (Rahim and Yousefi, 2012) 
M.M. Sadeghiazad and F. Choobdar Rahim / Energy Research Journal 2020, Volume 11: 1.11 DOI: $10.3844 /$ erjsp.2020.1.11

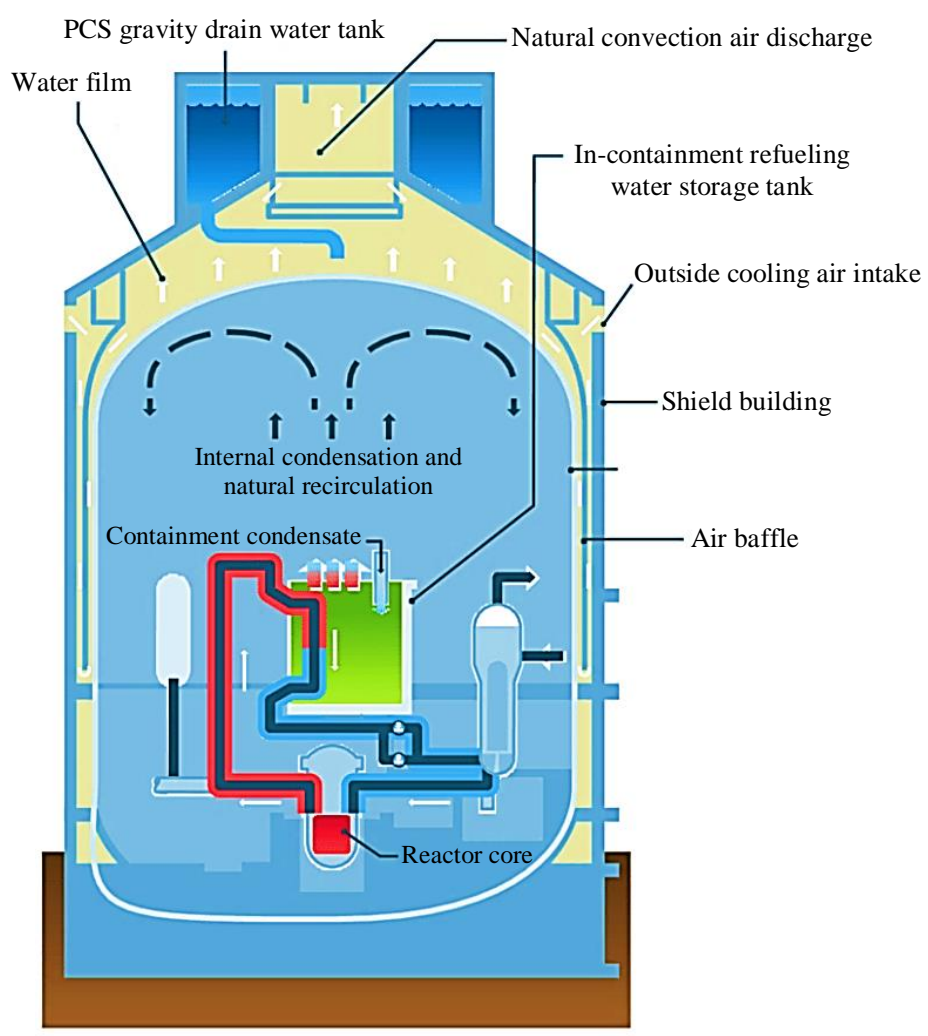

Fig. 2: AP1000 Passive Containment Cooling System (LLC, 2003)

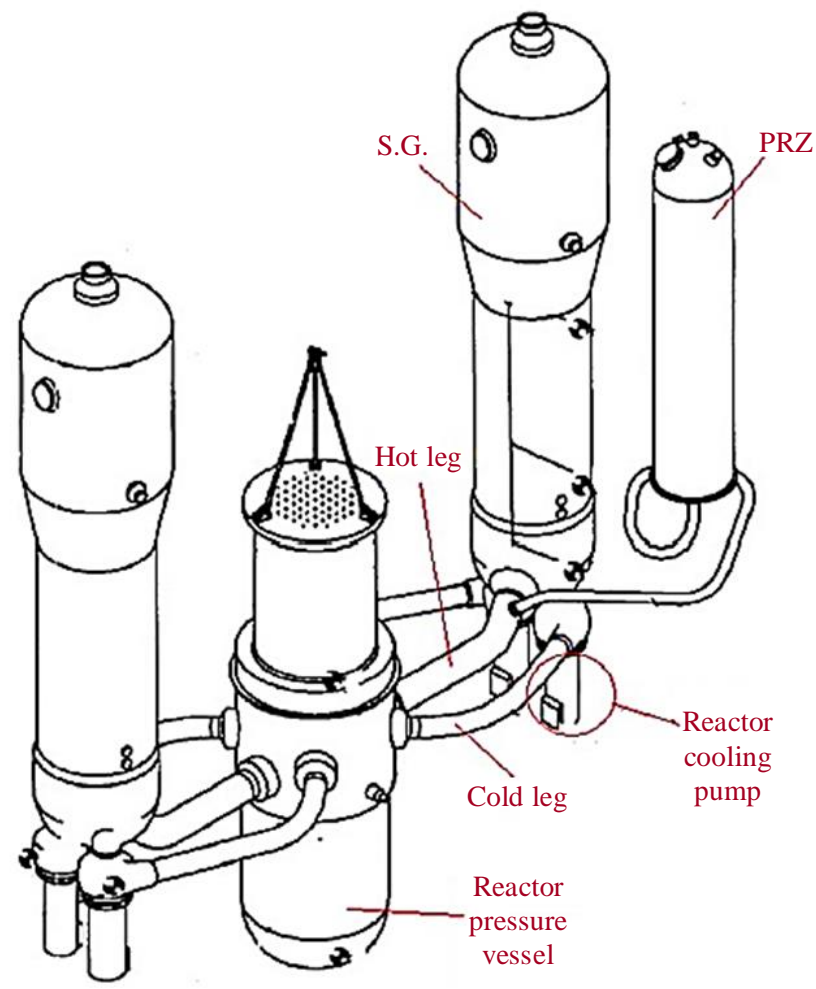

Fig. 3: Reactor cooling system in AP1000 (Hung et al., 2015) 


\section{Mathematical Formulation}

There are several methods by which the containment modeling is performed. In single volume analysis, single volume, temperature and pressure are assumed for the whole containment. In light water reactor, the release of the primary or secondary cooling within the containment regarded as a postulated accident in the Containment Pressurization Process. There are two interesting parameters for the containment's structural considerations including the magnitude of the peak pressure and the time to reach it. With the occurrence of rapturing of either the primary or the secondary coolant loops, the fluid can be released within the containment. In both cases, it is assumed that the blow-down begins once the pipe rapture occurred. There are several factors on which the final state of water/air mixture depends: (1) Initial mass and thermodynamic state of both water in the reactor and air in the containment; (2) the fluid's release rate into the containment and the possible heat sources or sinks involved; (3) the possibility for exothermic chemical reactions; and (4) the core decay heat (Todreas and Kazimi, 1990). In the transient conditions' analysis, the following equation has been derived by applying the first law of thermodynamics in three subsections including air of containment, the initial water vapor in the containment air and the water discharged into the containment from the primary system:

$$
\begin{aligned}
& \frac{d}{d t}\left(m_{a} u_{a}+m_{w c} u_{w c}+m_{w p d} u_{w p d}+m_{w p r} u_{w p r}\right) \\
& =\dot{Q}_{n-w p r}-\sum_{i} \dot{Q}_{i-s t}
\end{aligned}
$$

Upon integration of Equation (1) from the time of $t$ to a later time $t+\Delta t$ during the discharge process, below equation is obtained:

$$
U^{t+\Delta t}-U^{t}=Q_{n-w p r}^{t+\Delta t}-\sum_{i} Q_{i-s t}^{t+\Delta t}
$$

Where:

$$
\begin{aligned}
& U^{t+\Delta t}=m_{a} u_{a}^{t+\Delta t}+\left(m_{w c}^{t}+m_{w p d}^{t+\Delta t}\right) u_{w c}^{t+\Delta t}+m_{w p r}^{t+\Delta t} u_{w p}^{t+\Delta t} \\
& U^{t}=m_{a} u_{a}^{t}+m_{w c}^{t} u_{w c}^{t}+m_{w p r}^{t} u_{w p}^{t}
\end{aligned}
$$

The discharged primary mass, $m_{w p r}^{t+\Delta t}$, is obtained by integrating the break flow rate, $\dot{m}(t)$ over the interval $t$ to $t+\Delta t$ :

$$
m_{w p d}^{t+\Delta t}=m_{w p d}^{t}+\int_{t}^{t+\Delta t} \dot{m}(t) d t
$$

Upon rupture, the system coolant flows into the control volume at the rate of $\dot{m}(t)$. The control volume shape remains constant with time and there is no shaft work. Therefore the first law for a control volume is written as:

$\dot{U}_{c . v .}^{t}=\dot{m}(t) h_{p}(t)+\dot{Q}_{w p r-c}-\dot{Q}_{c-s t}$

Integrating between times $t$ and $t+\Delta t$, Equation (4) becomes:

$U^{t+\Delta t}-U^{t}=+\int_{t}^{t+\Delta t} h_{p}(t) \dot{m}(t) d t+Q_{w p r-c}^{t+\Delta t}-Q_{c-s t}^{t+\Delta t}$

So for the control volume there exists:

$$
\begin{aligned}
& U^{t+\Delta t}=m_{a} u_{a}^{t+\Delta t}+\left(m_{w c}^{t}+m_{w p d}^{t+\Delta t}\right) u_{w c}^{t+\Delta t} \\
& U^{t}=m_{a} u_{a}^{t}+m_{w c}^{t} u_{w c}^{t}
\end{aligned}
$$

Equation (5) Becomes:

$$
\begin{aligned}
& m_{a} u_{a}^{t+\Delta t}+\left(m_{w c}^{t}+m_{w p d}^{t+\Delta t}\right) u_{w c}^{t+\Delta t} \\
& =m_{a} u_{a}^{t}+m_{w c}^{t} u_{w c}^{t}+\int_{t}^{t+\Delta t} h_{p}(t) \dot{m}(t) d t+Q_{w p r-c}^{t+\Delta t}-Q_{c-s t}^{t+\Delta t}
\end{aligned}
$$

Containment condition histories can be evaluated by Equation (6) in the following manner. First obtain the break flow rate, $\dot{m}(t)$ and the heat transferred from the coolant remaining in the vessel to the containment and the heat transferred to the containment structures $Q_{w p r-c}$ and $Q_{c-s t}$, respectively, by transient thermal analysis $\left(Q_{\text {wpr-c }}\right.$ has been neglected in this model). Primary system enthalpy is obtained in a manner analogous to that described for primary system internal energy after Equation (3) (Zheng Limin, 2016).

Analysis of equilibrium pressure conditions with respect to time are achieved upon completion of the blow-down process and establishment of pressure equilibrium between the contents of the containment vessel and the primary system. Equation (3) is still applicable, but the new state $t+\Delta t$ is the one after completion of blowdown and achievement of pressure equilibrium. Hence $u_{w c}^{t+\Delta t}$ and $u_{w p}^{t+\Delta t}$ are identical and at the state $t$ all of the primary coolant is in the primary system. So that Equation (2) becomes:

$U^{t+\Delta t}-U^{t}=Q_{n-w p r}^{t+\Delta t}-\sum_{i} Q_{i-s t}^{t+\Delta t}$

Where:

$$
\begin{aligned}
& U^{t+\Delta t}=m_{a} u_{a}^{t+\Delta t}+\left(m_{w c}^{t}+m_{w p}\right) u_{w c}^{t+\Delta t} \\
& U^{t}=m_{a} u_{a}^{t}+m_{w c}^{t} u_{w c}^{t}+m_{w p} u_{w p}^{t}
\end{aligned}
$$

In control volume approach the heat loss to the structures is re expressed as $Q_{c-s t}$ (Saiu and Frogheri, 2005): 
$U^{t+\Delta t}-U^{t}=Q_{n-w p r}^{t+\Delta t}-Q_{c-s t}^{t+\Delta t}$

Interpretation the energy balance of Equation (8) yields:

$m_{w}\left(u_{w}^{t+\Delta t}-u_{w}^{t}\right)+m_{a} c_{v a}\left(T^{t+\Delta t}-T_{a}^{t}\right)=Q_{n-w p r}^{t+\Delta t}-Q_{c-s t}^{t+\Delta t}$

And:

$$
\begin{aligned}
& m_{w} u_{w}^{t} \equiv m_{w a} u_{w a}^{t}+m_{w p} u_{w p}^{t} \\
& m_{w} u_{w}^{t+\Delta t} \equiv\left(m_{w a}+m_{w p}\right) u_{w}^{t+\Delta t} \\
& Q_{n-w p r}=Q_{w p r-c}+Q \text { Which } Q_{w p r-c}=0
\end{aligned}
$$

Equation (9) could be rewritten to express the water conditions separately as primary water and water in air:

$$
\begin{aligned}
& m_{w p d}^{t+\Delta t}\left(u_{f}^{t+\Delta t}+x_{s t 1} u_{f g}^{t+\Delta t}-u_{w p}^{t}\right)+m_{w a}^{t}\left(u_{f}^{t+\Delta t}+x_{s t 1} u_{f g}^{t+\Delta t}-u_{w a}^{t}\right) \\
& +m_{a} C_{v a}\left(T^{t+\Delta t}-T_{a}^{t}\right)=Q^{t+\Delta t}-Q_{c-s t}^{t+\Delta t}
\end{aligned}
$$

$Q^{t+\Delta t}$ is produced by input mass flow to the containment, $Q^{t+\Delta t}=\dot{m}_{w p d}^{t+\Delta t} h^{t+\Delta t} \Delta t$ and $Q_{c-s t}^{t+\Delta t}$ has been assumed to zero, then the analysis of peak pressure and temperature are modeled in no heat transfer condition. The results will show that in this condition, thermalhydraulic parameters will pass their design values or not. Whereas the water vapor and air are intermingled gases, each exerting its partial pressure, the liquid is agglomerated and at a pressure equal to the total pressure. From Dalton's law of partial pressures:

$$
p^{t+\Delta t}=p_{w}^{t+\Delta t}\left(T^{t+\Delta t}\right)+p_{a}^{t+\Delta t}
$$

where, $p^{t+\Delta t}$ is the pressure of mixture, $p_{w}^{t+\Delta t}$ is partial pressure of the saturated water vapor corresponding to $T^{+\Delta t}$, $p_{a}^{t+\Delta t}$ is partial pressure of air corresponding to $T^{t+\Delta t}$ and from the associated fact that each mixture component occupies the total volume, below equation is obtained:

$V_{T}^{t+\Delta t}=m_{w}^{t+\Delta t} v_{w}^{t+\Delta t}\left(T_{s a t}^{t+\Delta t}\right) \simeq m_{a} v_{a}\left(T^{t+\Delta t}, p_{a}^{t+\Delta t}\right)$

Introducing the definition of the steam static quality $\left(x_{s t}\right)$ in the containment and treating air as a perfect gas, Equation (12) becomes:

$$
V_{T}^{t+\Delta t}=m_{w}^{t+\Delta t}\left[v_{f}^{t+\Delta t}+x_{s t 2} v_{f g}^{t+\Delta t}\left(T_{s a t}^{t+\Delta t}\right)\right] \simeq \frac{m_{a} R_{a} T^{t+\Delta t}}{p_{a}^{t+\Delta t}}
$$

From Equation (13):

$$
x_{s t 2}=\frac{\frac{V_{T}^{t+\Delta t}}{m_{w}^{t+\Delta t}}-v_{f}^{t+\Delta t}}{v_{f g}^{t+\Delta t}}
$$

Where:

$$
V_{T}^{t+\Delta t}=\sum_{t=1}^{t+\Delta t}\left(m_{w p d}^{t} v_{w p d}^{t}\right)+V_{c}
$$

Establishment of the initial air pressure $\left(p_{a}^{t}\right)$ in the containment should consider the water vapor present. This correction on $p_{a}^{t}$ is minor but illustrates the use of Dalton's law of partial pressures. The initial conditions are characteristically stated in terms of a relative humidity $(\phi)$, the dry bulb temperature $\left(T_{a}^{t}\right)$ and the total pressure $\left(p^{t}\right)$. From the definition of relative humidity, the saturated water vapor pressure for the given initial condition $\left(p_{w a}^{t}\right)$ is given by:

$p_{w a}^{t}=\varphi^{t} p_{s a t}\left(T_{a}^{t}\right)$

Therefore by using Dalton's law of partial pressures, it is reached:

$p_{a}^{t}=p^{t}-p_{w a}^{t}$

And by the perfect gas law:

$m_{a}=\frac{p_{a}^{0} V_{c}}{R_{a} T_{a}^{0}}$

Equation (18) shows the mass of initial water in the containment:

$m_{w a}^{0}=\frac{V_{\mathrm{c}}}{v_{w a}^{0}}$

And primary discharged water is:

$V_{w p d}^{t}=m_{w p d}^{t} v_{w p d}^{\mathrm{t}}$

Where the total mass of water is:

$m_{w}^{t+\Delta t}=\sum_{t=1}^{t+\Delta t} m_{w p d}^{t}+m_{w a}^{0}$

Now all of unknown parameters are depend on $T^{+\Delta t}$, then with conjecture of this value and checking it, all of unknown variables could be determined. If the absolute difference of static qualities which are already denoted ( $x_{s t 1}$ in Equation (10) and $x_{s t 2}$ in Equation (14) is less than an error function, then other parameters in subsequent conditions will be determined. These variables are:

$$
p_{w}^{t+\Delta t}=f_{\text {sat. }}\left(T^{t+\Delta t}\right)
$$


which is achieved from saturation library and $p_{a}^{t+\Delta t}=\frac{m_{a} R_{a} T^{t+\Delta t}}{V_{T}^{t+\Delta t}}$ and totally:

$p^{t+\Delta t}=p_{w}^{t+\Delta t}+p_{a}^{t+\Delta t}$

Else, if guessed value is not converged, then another value should be conjectured. which is inserted to the $Q_{c-s t}$ sub program which will be explained in the next section.

\section{Heat Transfer}

In this section, the heat transferred from inside of containment to outside, denotes by $Q_{c-s t}$, is evaluated to be used in the mathematical formulations. The temperature conjecturing at the outer surface of shield building, the outer gap (down-comer, denotes by gap1 in the initial condition) and the inner gap (riser, denotes by gap2) are the bases of the heat transfer modeling. By comparing the new value obtained from other thermal hydraulic parameters which are calculated from the estimated value using the heat transfer relations with the guessed value, a correction for the process is achieved.

These relations representing conduction and convection in solid resistance (such as shield building, air baffle and carbon steel containment) and in the fluid layers (such as ambient, down-comer, riser and inside the containment, respectively, in 1-D cylindrical (radial) coordinates. The absolute difference between the guessed and estimated values for every conjectured parameter (such as down-comer's temperature) should be less than an error function. If this condition is satisfied, the estimated value is correct, otherwise the process should be iterated with a new guessed value. With the further penetration of heat transfer into the containment as well as estimating the temperatures of the wall, despite the correction for each temperature of the gap, the containment's temperature of the inner surface is obtained. The following relation (Hung et al., 2015) is used to obtained h_(cont.) by using this temperature and internal air/steam mixture temperature defined in the mathematical modeling:

$h_{f g 1}=h_{f g}+0.68 C_{p f}\left(T_{\text {sat. }}-T_{\text {in.cont. }}\right)$

$\Rightarrow h_{\text {cont. }}=\left\{0.943\left(\frac{9.8 \frac{1}{v_{f}}\left(\frac{1}{v_{f}}-\frac{1}{v_{g}}\right) K_{f}^{3} h_{f g 1}}{\mu_{f}\left(T_{\text {sat. }}-T_{\text {in.cont. }}\right) l}\right)^{0.25}\right\}$ below:
$T_{\text {in.cont. }}=T_{\text {sat. }}-\left(\frac{Q_{c-s t}}{2 \pi l h_{\text {cont. }} r_{\text {in.cont. }}}\right)$

In a case wherein the absolute difference between this value and the value estimated in previous iteration is less than the error function, then the value estimated for Q-(c-st) based on the prime estimated outer surface's temperature of shield building is correct, otherwise the whole process should be iterated again with another outer surface's temperature of shield building so that the condition satisfied. The iteration is continued until a correct value (converged one) is achieved. The all above-mentioned procedures are just iterated in a single step, while each should be performed as long as each interior air/steam mixture temperature is estimated by the main modeling and are used as inputs in the heat transfer program The parameter $h_{\text {cont }}$ is only used inside the containment not in the gaps. According to the following correlations (Incropera, 2002), the parameter $\mathrm{h}$ (convection heat transfer coefficient) is evaluated in every step.

$\overline{N u}_{\delta}=\left\{0.825+\frac{0.387 R a_{\delta}^{\frac{1}{6}}}{\left[1+\left(\frac{0.492}{\operatorname{Pr} \operatorname{Pr}}\right)^{\frac{9}{16}}\right]^{\frac{8}{27}}}\right\}^{2}$

$h=\frac{\overline{N u}_{\delta} K}{l}$

And convection heat transfer coefficient is obtained. In the Fig. 4 is shown the thermal resistances from inside the safety containment to the outside environment.

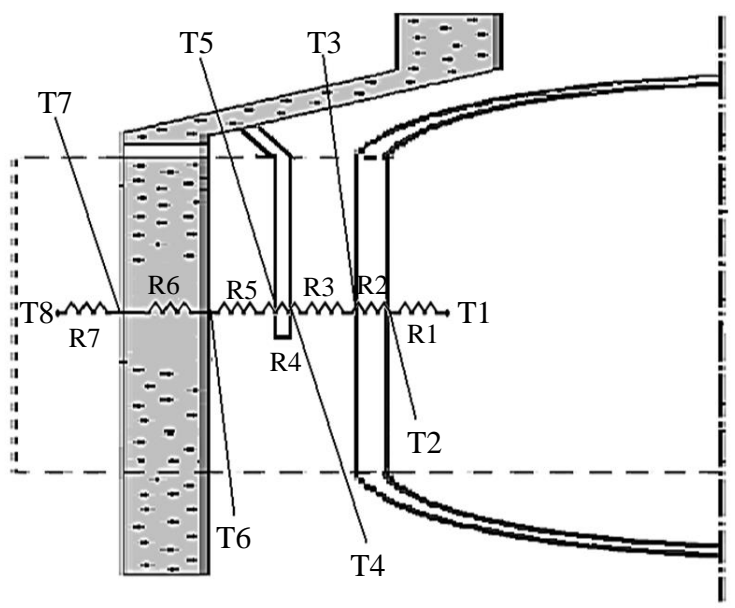

Fig. 4: Multilayer heat resistance in AP1000 containment 


\section{Results}

Modeling is performed by MATLAB R20016 software. Released mass flow and enthalpy (Fig. 4 and. 5) are used as matrix from (Xie, 2017). The main purpose is determination of pressure and temperature variations with respect to time (Fig. 6 and 7). In Table 1, initial conditions of modeling are presented:

1) From (DCD, 2007).

2) Interior and exterior areas of containment are divided into two sections. First section which is cylindrical and being evaluated from operation floor elevation till top end of cylindrical portion elevation and the second section is the dome portion that is calculated from top end of cylindrical portion elevation till the top of air baffle elevation (DCD, 2007). Area calculations have been performed using the rotating curve formula.

3) Cylindrical portion of the shield building is calculated in modeling. Heat transfers from conical portion and air exhaust are ignored.

4) Total area of air baffle is evaluated in modeling (DCD, 2007). This area is based on references data and some calculations for knuckle portion, which has used rotating curve formula.

5) From calculations based on measurements.

6) From (DCD, 2007).

7) Hypothetical values (based on some measurements and calculations).
8) From (DCD, 2007).

9) From (DCD, 2007).

10) From (DCD, 2007).

11) Near to the initial condition (DCD, 2007).

12) From (DCD, 2007).

13) From (DCD, 2007). $\dot{m}_{\text {air }}=\rho_{\text {air }} A_{\text {AirInlets }}$

14) $=1.16\left(\mathrm{~kg} / \mathrm{m}^{3}\right)(15 \times 4.572 \times 1.9812)\left(\mathrm{m}^{2}\right) 5(\mathrm{~m} / \mathrm{s})$

$$
=788.05(\mathrm{~kg} / \mathrm{s})
$$

$A_{\text {AirInlets }}$ consists of 15 panels with 15 (ft) long (4.572 (m)) and 6.5 (ft) high (1.9812 (m)). The velocity of cooling air flow is assumed to be $5(\mathrm{~m} / \mathrm{s})$. The cooling air flow and PCCWST are participated in containment cooling system. But the effect of drained water from PCCWST is ignored in this model and the effect of air flow is just highlighted (Addition information is in reference (DCD, 2007). and Fig. 1).

15) (15) This active length consists of two parts, one part is cylindrical (41.7703 (m) which is obtained from measurement between operation floor elevation and end of cylindrical portion elevation) (DCD, 2007). and the other part is knuckle (6.0506 (m)) which is achieved from calculations (These evaluations are made by curve length formula calculations from end of cylindrical portion elevation till the top of air baffle elevation).

Table 1: Containment geometry and initial conditions

\begin{tabular}{|c|c|c|}
\hline Parameter & Description & Value \\
\hline$V_{c}^{(1)}$ & Containment volume & $58969.067\left(\mathrm{~m}^{3}\right)$ \\
\hline A out.cont. $^{(2)}$ & Active area of outer surface of containment & $5934.8567\left(\mathrm{~m}^{2}\right)$ \\
\hline$A_{\text {in.cont. }}{ }^{(2)}$ & Active area of inner surface of containment & $5922.1553\left(\mathrm{~m}^{2}\right)$ \\
\hline A $_{\text {conc. }}{ }^{(3)}$ & Active area of concrete shield building & $6552.1346\left(\mathrm{~m}^{2}\right)$ \\
\hline$A_{\text {AirBaffle }}^{(4)}$ & Active area of air baffle & $4258.6595\left(\mathrm{~m}^{2}\right)$ \\
\hline$A_{\text {gap } 1^{(5)}}$ & Active area of gap1 (down-comer) & $6183.729\left(\mathrm{~m}^{2}\right)$ \\
\hline$A_{\text {gap } 2^{(5)}}$ & Active area of gap2 (riser) & $5984.7455\left(\mathrm{~m}^{2}\right)$ \\
\hline$\delta_{\text {cont. }}{ }^{(6)}$ & Containment thickness & $0.0444(\mathrm{~m})$ \\
\hline$\delta_{g a p 2^{(7)}}$ & Riser thickness & $0.6561(\mathrm{~m})$ \\
\hline$\delta_{\text {AirBaffle }}{ }^{(7)}$ & Air Baffle Thickness & $0.015(\mathrm{~m})$ \\
\hline$\delta_{g a p 1^{(7)}}$ & Down-comer thickness & $0.6561(\mathrm{~m})$ \\
\hline$\delta_{\text {conc. }}{ }^{(8)}$ & Concrete shied building thickness & $0.9144(\mathrm{~m})$ \\
\hline$r_{\text {in.cont. }}{ }^{(9)}$ & Internal radius of containment & $19.812(\mathrm{~m})$ \\
\hline$r_{\text {in.cont. }}{ }^{(10)}$ & Internal radius of concrete shield building & $21.132(\mathrm{~m})$ \\
\hline$T_{\text {sato }}(11)$ & Initial interior temperature of containment (Saturated) & $48.8\left({ }^{\circ} \mathrm{C}\right)$ \\
\hline$\varphi_{0}^{(12)}$ & Initial relative humidity & 0 \\
\hline$P_{0 \text { cont. }}{ }^{(12)}$ & Initial containment pressure & $0.1082(M P a)$ \\
\hline$P_{\text {Hot }, \text { Leg. }}{ }^{(13)}$ & Hot leg pressure & $15.4994(M P a)$ \\
\hline$T_{\text {Hot,Leg. }}{ }^{(13)}$ & Hot leg temperature & $321\left({ }^{\circ} \mathrm{C}\right)$ \\
\hline$\dot{m}_{\text {air }}^{(14)}$ & Inlet air mass flow rate & $788.05(\mathrm{~kg} / \mathrm{s})$ \\
\hline$l^{(15)}$ & Active height of heat transfer (common in each thermal layer) & $47.8209(\mathrm{~m})$ \\
\hline
\end{tabular}




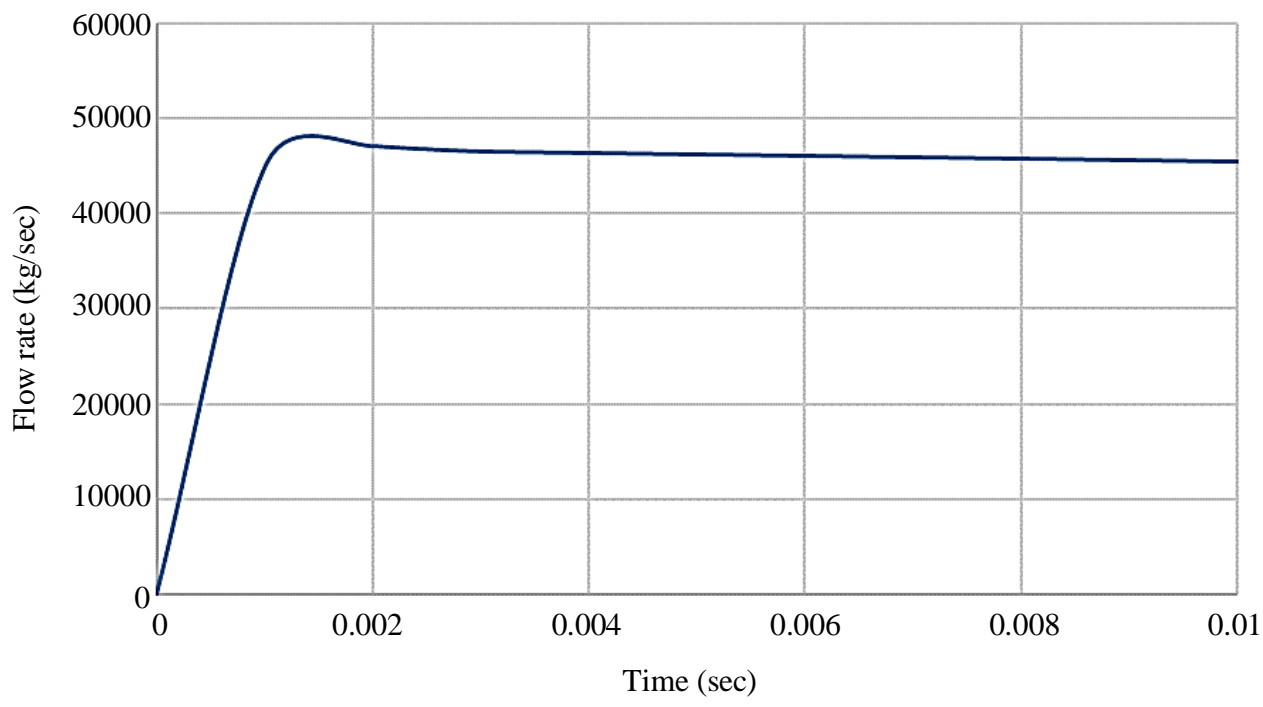

(a)

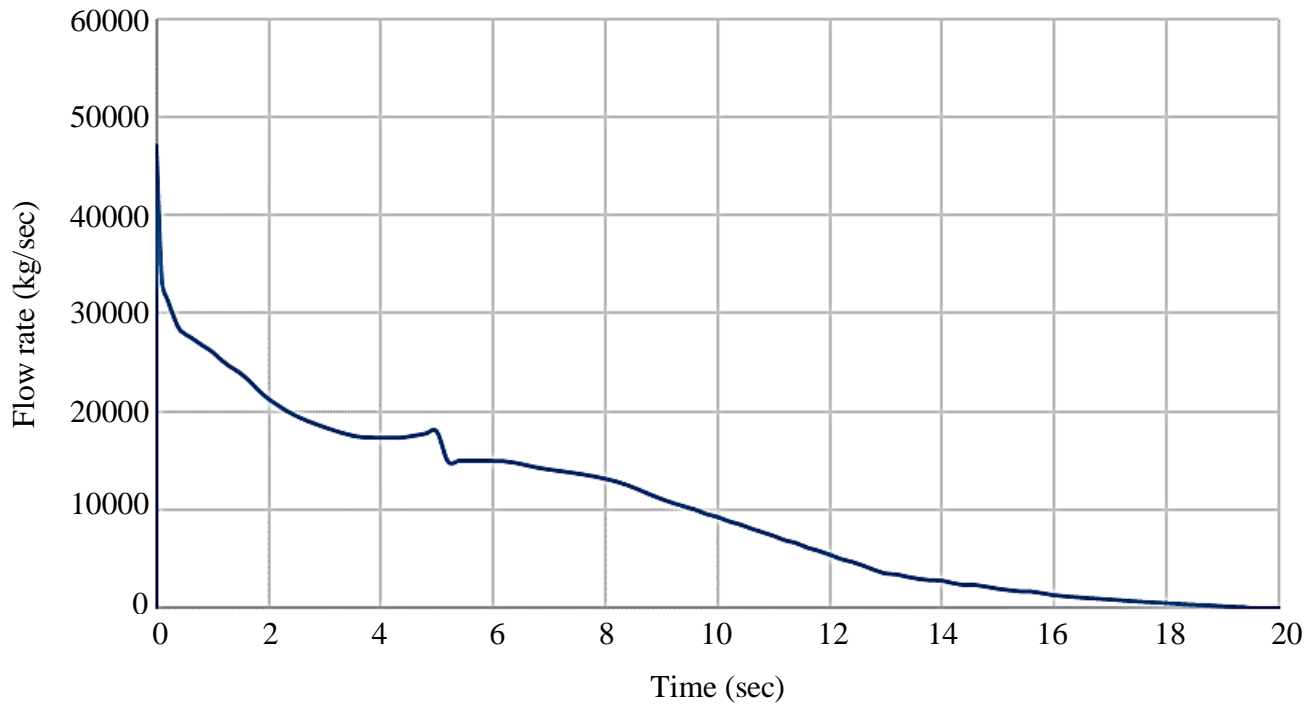

(b)

Fig. 5: Distribution of mass flow rate with time. (a) 0 to $0.01 \mathrm{sec}$, (b) 0 to $20 \mathrm{sec}$ (U.S.NRC, 2004)

In Fig. 5 is shown distribution of mass flow rate with time in DEHL accident, From Fig. 5a, it is cleared that the maximum of flow rate is in among between 0 to 0.002 (sec) and this is because of a big difference between pressure and temperature of water in Hot leg and interior atmosphere of containment in the break moment. Till second 20 the water flow is released to the containment, but from this second to end of blow-down.

Figure 6 shows the distribution of fluid enthalpy within the safety compartment over time. Which is directly related to the discharge mass flow from the broken Hot leg pipe into the safety containment.

In Fig. 7 is shown peak of pressure plot is located between 18 to 24 seconds and this is because of variations of input flow. In this figure with heat transfer model depend to when structure of containment has heat transfer with ambient. According to containment response at the moment of LOCA, the pressure increases very rapidly due to the initial blow-down event. The containment pressure eventually reaches a peak at about $20 \mathrm{~s}$ after the initiation of the event. At this time, evaporation of the passive containment cooling systems water effectively cools the containment shell and the pressure begins to decrease slowly.

In Fig. 8 is shown peak of temperature plot and this is because of variations of input flow. In this figure with heat transfer model depend to when structure of containment has heat transfer with ambient. In Table 2 the calculated results are compared with the existing results. 
M.M. Sadeghiazad and F. Choobdar Rahim / Energy Research Journal 2020, Volume 11: 1.11 DOI: 10.3844/erjsp.2020.1.11

Table 2: Summary of results with differences between model and result (Hung et al., 2015; U.S.NRC, 2004)

\begin{tabular}{|c|c|c|c|c|c|c|}
\hline $\begin{array}{l}\text { DEHL } \\
\text { Modeling } \\
\end{array}$ & $\begin{array}{l}\text { Pressure } \\
\text { Peak (kpa) }\end{array}$ & $\begin{array}{l}\text { Temperature } \\
\text { Peak }\left({ }^{\circ} \mathrm{C}\right)\end{array}$ & $\begin{array}{l}\text { Difference between } \\
\text { pressure } \\
\text { (U.S.NRC, 2004) }\end{array}$ & $\begin{array}{l}\text { Difference between } \\
\text { pressure } \\
\text { (Hung et al., 2015) }\end{array}$ & $\begin{array}{l}\text { Difference between } \\
\text { temperature } \\
\text { (U.S.NRC, 2004) }\end{array}$ & $\begin{array}{l}\text { Difference between } \\
\text { temperature } \\
\text { (Hung et al., 2015) }\end{array}$ \\
\hline DCD (U.S.NRC, 2004) & 345 & 213 & --- & --- & --- & --- \\
\hline Our Study & 396 & 180 & $12 \%$ & $5 \%$ & $15 \%$ & $6 \%$ \\
\hline
\end{tabular}

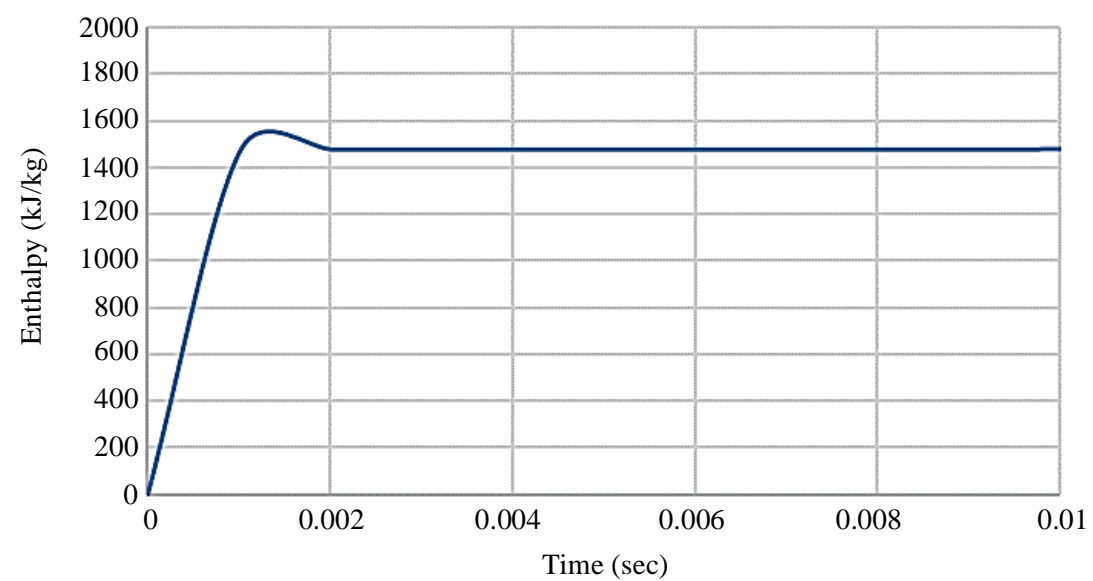

(a)

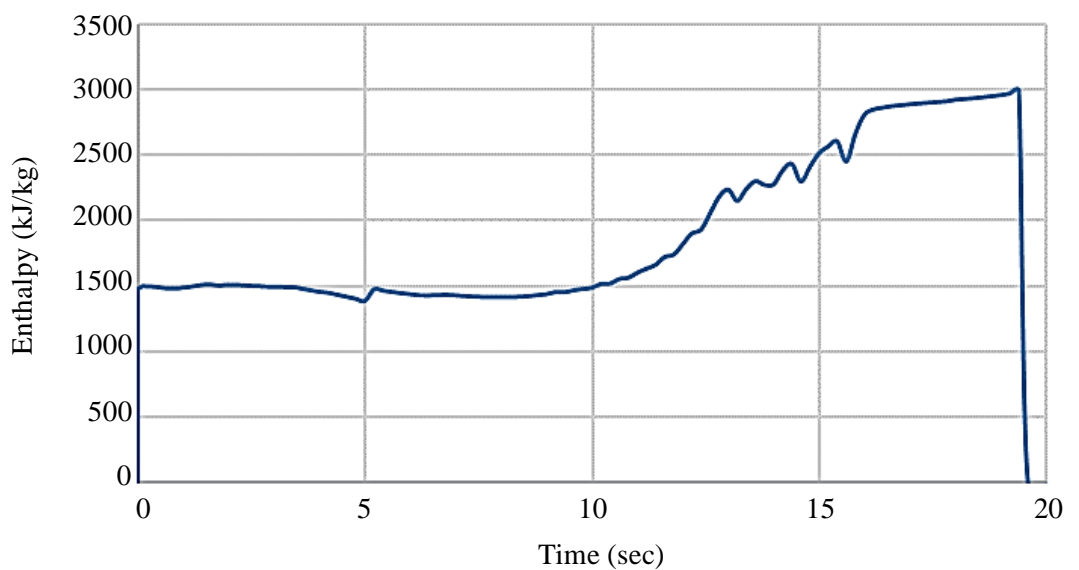

(b)

Fig. 6: Distribution flow enthalpy released with time (U.S.NRC, 2004)

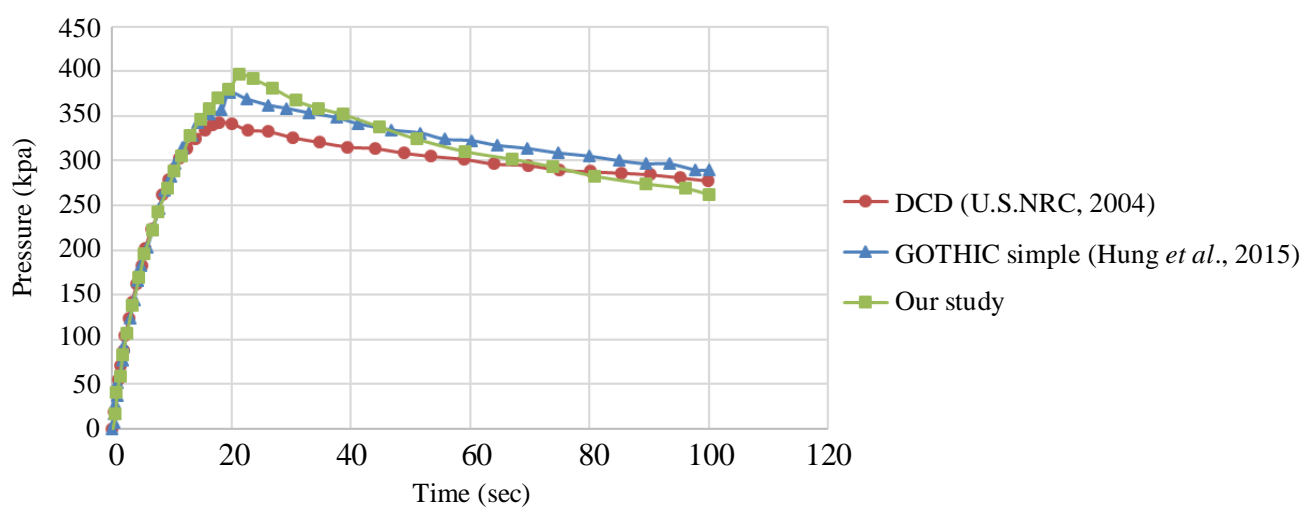

Fig. 7: Time variations of Pressure 


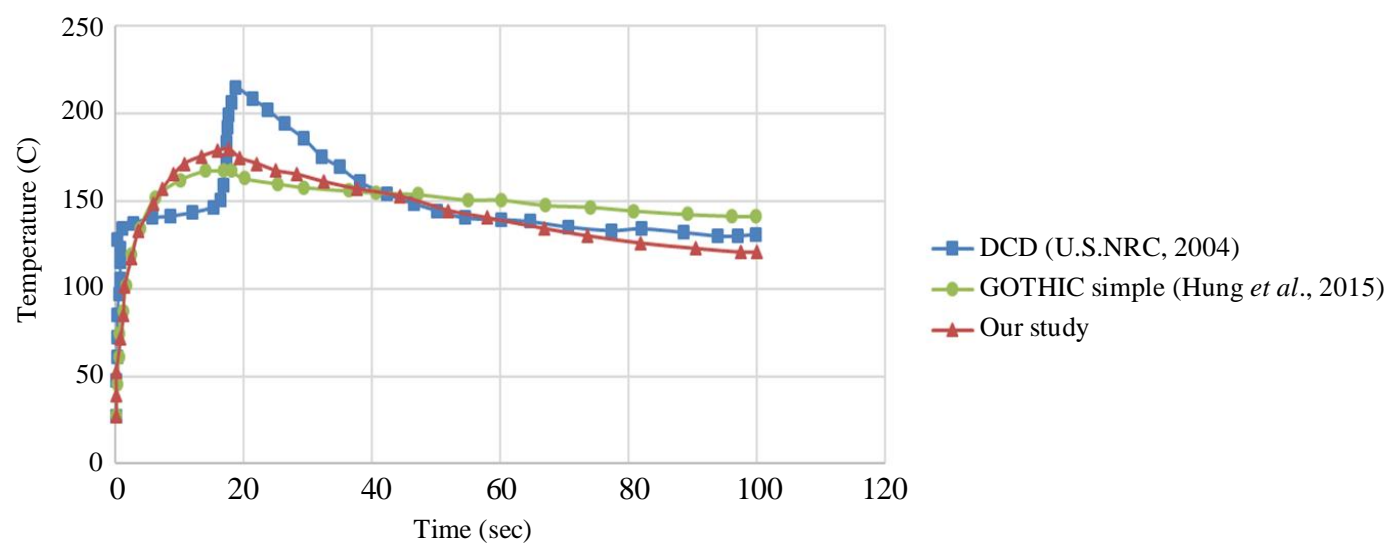

Fig. 8: Time variations of Temperature

\section{Conclusion}

During an LB-LOCA accident, a large amount of water-steam mixture can be flashed into the containment and the aim of the containment system is to avoid or limit the release of these to the environment by maintaining its integrity. The single-cell modeling on containment pressurization has been studied in this work. By comparing the results of the numerical modeling and that of the references (Hung et al., 2015; U.S.NRC, 2004), it can be found that using the single volume method for twophase simulation of the accident in AP1000 reactor is acceptable. Since there are little differences between the results of the modeling and that of the references (Hung et al., 2015; U.S.NRC, 2004), it is concluded that mathematical procedures and conjectures in transients, equilibrium conditions, along with receivable are considered as the appropriate assumptions for the AP1000 reactors. According to containment response at the moment of LOCA, the pressure increases very rapidly due to the initial blow-down event. The containment pressure eventually reaches a peak at about $20 \mathrm{~s}$ after the initiation of the event. At this time, evaporation of the passive containment cooling systems water effectively cools the containment shell and the pressure begins to decrease slowly. In short term conditions with heat transfer, peak of pressures is below design pressure $(0.5013 \mathrm{MPa})$ (U.S.NRC, 2004). This verity is clear that without any heat transferring, safety is not possible. Containment is the last safety barrier in nuclear power plants; Hence in these worst conditions, the probability of leakage from containment to atmosphere is too close to unity. Therefore, the importance of passive safety systems is more prominent.

\section{Nomenclature of Mathematical Formulation is Shown Below}

$M_{a} \quad=$ The mass of containment air

\begin{tabular}{|c|c|c|}
\hline$m_{w c}$ & $=$ & Water vapor in the containment air \\
\hline$m_{w p}$ & $=$ & $\begin{array}{l}\text { Water initially in the primary (or } \\
\text { secondary) system depending on rupture } \\
\text { assumption }\end{array}$ \\
\hline$m_{w p d}$ & $=$ & $\begin{array}{l}\text { Any given time, of the mass } m_{w p} \text {, has } \\
\text { discharged into the containment }\end{array}$ \\
\hline$m_{w p r}$ & $=$ & $\begin{array}{l}\text { Remained portion of } m_{w p} \text { in the primary } \\
\text { system }\end{array}$ \\
\hline$V_{c}$ & $=$ & The net free volume of containment, \\
\hline$V_{p}$ & $=$ & The volume of primary system \\
\hline$V_{T}$ & $=$ & The total volume $\left(V_{c}+V_{p}\right)$ \\
\hline$m_{w a}$ & $=$ & $\begin{array}{l}\text { The mass of water initially in the } \\
\text { containment air }\end{array}$ \\
\hline$m_{w}$ & $=$ & $\begin{array}{l}\text { The mass of water, which is composed of } \\
\text { water vapor initially in the air and water } \\
\text { or water and steam initially in the failed } \\
\text { system, i.e., } m_{w a}+m_{w p}\end{array}$ \\
\hline$u=u(T, v)$ & $=$ & $\begin{array}{l}\text { The internal energy per unit mass } \\
\text { defined with respect to a reference } \\
\text { internal energy } u_{0}\left(T_{0}, v_{0}\right) \text { per unit mass }\end{array}$ \\
\hline$u_{w}$ & $=$ & $\begin{array}{l}\text { The internal energy of the water in the } \\
\text { containment air and the water in the } \\
\text { failed system, i.e., } u_{w a} \text { and } u_{w p}\end{array}$ \\
\hline$c_{v a}$ & $=$ & Specific heat of air at constant volume \\
\hline$Q_{n-w p r}$ & $=$ & $\begin{array}{l}\text { Heat transferred from fuel to water } \\
\text { remaining of primary cycle }\end{array}$ \\
\hline$Q_{w p r-c}$ & $=$ & $\begin{array}{l}\text { Heat transferred from water remaining of } \\
\text { primary cycle to control volume }\end{array}$ \\
\hline$Q_{c-s t}$ & $=$ & $\begin{array}{l}\text { Heat transferred from control volume to } \\
\text { structures }\end{array}$ \\
\hline$T_{a}$ & $=$ & Air temperature \\
\hline$T$ & $=$ & $\begin{array}{l}\text { Temperature for the air/steam mixture in } \\
\text { the containment }\end{array}$ \\
\hline$P$ & $=$ & The pressure of mixture \\
\hline$p_{w}$ & $=$ & $\begin{array}{l}\text { Partial pressure of the saturated water } \\
\text { vapor corresponding to } T\end{array}$ \\
\hline$p_{a}$ & $=$ & Partial pressure of air corresponding to $T$ \\
\hline$\dot{m}$ & $=$ & Mass flow rate \\
\hline$x_{s t}$ & $=$ & Static mass quality, \\
\hline
\end{tabular}




\section{Indices}

Subscripts $w$ and $f$ refer to water, $g$ refers to vapor, $f g$ refers to evaporation, $a$ refers to air, sat refers to saturation condition and superscripts $t$ refers to time $t$ and $t+\Delta t$ is one time step beyond the time $t$.

\section{Author's Contributions}

All the authors contributed equally to prepare, develop and carry out this manuscript.

\section{Ethics}

This article is original. The corresponding author confirms that all of the other authors have read and approved the manuscript and no ethical issues involved.

\section{References}

Broxtermann, P. and H.J. Allelein, 2013. Simulation of AP1000's passive containment cooling with the German containment code system COCOSYS. Nuclear Eng. Design, 261: 326-332.

DOI: 10.1016/j.nucengdes.2012.09.038

Choobdar Rahim, F. and P. Yousefi, 2012. Simulation of the AP1000 reactor containment pressurization during loss of coolant accident. Progress Nuclear Energy, 60: 129-134. DOI: 10.1016/j.pnucene.2012.05.009

Choobdar Rahim, F., M. Rahgoshay and S.K.H. Mousavian, 2012. A study of large break LOCA in the AP1000 reactor containment. Progress Nuclear Energy, 54: 132-137.

DOI: $10.1016 /$ j.pnucene.2011.07.004

DCD, 2007. The AP1000 European DCD, UK AP1000 Safety. Security and Environmental Report.

Hung, Z.Y., Y.M. Ferng, W.S. Hsu, B.S. Pei and Y.S. Chen, 2015. Analysis of AP1000 containment passive cooling system during a loss-of-coolant accident. Annals Nuclear Energy, 85: 717-724.

DOI: 10.1016/j.anucene.2015.06.027

Hung, Z.Y., Y.M. Ferng, W.S. Hsu, B.S. Pei and Y.S. Chen, 2015. Analysis of AP1000 containment passive cooling system during a loss-of-coolant accident. Annals Nuclear Energy, 85: 717-724.

DOI: 10.1016/j.anucene.2015.06.027

Incropera, F.P., 2002. Introduction to Heat Transfer. 4th Edn., Wiley, New York, ISBN-10: 0471386499, pp: 892.

LLC, 2003. The Westinghouse AP1000 advanced nuclear plant. Plant Description, Westinghouse Electric Co., LLC.

Noori-Kalkhoran, O., A.S. Shirani and R. Ahangari, 2016. Simulation of containment pressurization in a large break-loss of coolant accident using single-cell and multicell models and CONTAIN code. Nuclear Eng. Technol., 48: 1140-1153.
Oriolo, F. and S. Paci, 2000. Heat and mass transfer models in LWR containment systems. Nuclear Eng. Design, 204: 233-250.

DOI: $10.1016 / \mathrm{S} 0029-5493(00) 00314-9$

Rahim, F.C. and P. Yousefi, 2012b. Simulation of the AP1000 reactor containment pressurization during loss of coolant accident. Progress Nuclear Energy, 60: 129-134. DOI: 10.1016/j.pnucene.2012.05.009

Saiu, G. and M.L. Frogheri, 2005. AP1000 nuclear power plant overview. ANSALDO Energia S.p.ANuclear Division Corso Perone.

Sheykhi, S., S. Talebi, M. Soroush and E. Masoumi, 2017. Thermal-hydraulic and stress analysis of AP1000 reactor containment during LOCA in dry cooling mode. Nuclear Sci. Techniques. DOI: $10.1007 / \mathrm{s} 41365-017-0233-8$

Todreas, N.E. and M.S. Kazimi, 1990. Nuclear systems 1 thermal hydraulic fundamentals. Massachusetts Institute of Technology, Hemisphere Publishing Corporation.

U.S.NRC, 2004. AP1000 design control document. U.S. NRC. Engineered Safety Features Revision 14 Revision 3 Tier 2. Westinghouse.

Xie, H., 2017. Numerical simulation of AP1000 LBLOCA with SCDAP/RELAP 4.0 code. J. Nuclear Sci. Technol., 54: 969-976. DOI: $10.1080 / 00223131.2017 .1331766$

Yang, J., W.W. Wang, S.Z. Qiu, W.X. Tian and G.H. Su et al., 2012. Simulation and analysis on 10-in. cold leg small break LOCA for AP1000. Annals Nuclear Energy, 46: 81-89. DOI: $10.1016 /$ j.anucene.2012.03.007

Yousif, E., Z. Zhang, Z. Tian and H.R. Ju, 2017. Simulation and analysis of small break LOCA for AP1000 using RELAP5-MV and its comparison with NOTRUMP code. Sci. Technol. Nuclear Installat. DOI: 10.1155/2017/4762709

Zheng Limin, L.L., 2016. Analysis of reactor coolant system leak for AP1000 nuclear power plant. Nuclear Techniques, 39: 90603-090603. DOI: 10.11889/j.0253-3219.2016.hjs.39.090603 